\title{
Neonatal Immune State Is Influenced by Maternal Allergic Rhinitis and Associated With Regulatory T cells
}

\author{
Lu Tan, ${ }^{1}$ Jing $\mathrm{Ou}_{1}^{1}$ Zezhang Tao, ${ }^{1,2}$ Yonggang Kong, ${ }^{1,2} Y u X^{1,2 *}$ \\ ${ }^{1}$ Department of Otolaryngology-Head and Neck Surgery, Renmin Hospital of Wuhan University, Wuhan, China \\ ${ }^{2}$ Research Institute of Otolaryngology-Head and Neck Surgery, Renmin Hospital of Wuhan University, Wuhan, China
}

This is an Open Access article distributed under the terms of the Creative Commons Attribution Non-Commercial License (http://creativecommons.org/licenses/by-nc/4.0/) which permits unrestricted non-commercial use, distribution, and reproduction in any medium, provided the original work is properly cited.

Purpose: Maternal influences contribute to the origin of allergic diseases, but the mechanisms are not clear. The current literature prompted the role of epigenetics in the development of allergic diseases. We sought to investigate the roles of regulatory $T$ (Treg) cells and Forkhead box p3 (Foxp3) DNA methylation in the process of maternal transmission of allergic rhinitis (AR) susceptibility. Methods: BALB/c female mice (AR mother) were sensitized by intraperitoneal injection of Dermatophagoides pteronyssinus (Der p) 1 on day 1 and 7 . Then they mated with normal male mice on day 8 . From day 21 to 28 , the female mice were intranasal challenged with Der $p 1$ continuously. The normal controls were given with normal saline in the same way. On postnatal day 3, Female mice and their offspring were sacrificed to detect their histopathology in nasal mucosae, cytokines in sera of mother and spleen homogenates of offspring, Treg cells count, Foxp3 mRNA expressions, and Foxp3 DNA methylation levels in spleens. Results: Compared with the normal controls, neonatal offspring of Der $p$ 1-stimulated female mice (AR offspring) showed the elevation of interleukin (IL)-4 $(P<0.01)$ and IL-17 $(P<0.01)$, the submission of IL-10 $(P<0.01)$ in spleen homogenates. Further, Treg cells count in AR offspring decreased remarkably compared with the normal offspring $(P<0.01)$. Though the difference of Foxp3 DNA methylation level between AR offspring and normal control offspring was not obvious, correlation analysis demonstrated that there was significantly positive correlation between Foxp3 DNA methylation level of mother and that of offspring $(r=0.803, P<0.01)$. Conclusions: Under the influence of Maternal $A R$, their neonatal offspring develop into T-helper type 2 (Th2) dominant immune state, which is closely associated with the recession of Treg cells. Foxp3 DNA methylation may be a mechanism responsible for that maternal effect but still need more studies to ensure.

Key Words: Allergic rhinitis; maternal; offspring; regulatory T cell; DNA methylation; forkhead box p3

\section{INTRODUCTION}

With the prevalent trend of allergic rhinitis (AR) around the world, ${ }^{1-3}$ the familial aggregation of AR patients and heritability of AR are noticed by researchers. Having a family history of allergy is a main risk factor for AR. Multiple studies ${ }^{4-6}$ have demonstrated that maternal allergic diseases confer greater risk of allergic diseases to offspring than does paternal diseases.

The classic view in immunology indicates that the occurrence of AR is the result of T-helper type 2 (Th2) polarization. ${ }^{7}$ Besides T-helper type 1 (Th1)/Th2 imbalance, regulatory T (Treg) cells are also closely correlated with the onset of AR. ${ }^{8}$ Decrease of Treg cells count and/or defectiveness of its function were detected in patients with allergic diseases. ${ }^{9}$ However, studies concerning the roles of Treg cells in the process of maternal transmission of AR susceptibility are limited and contradictory. It was found that Treg cells were decreased in the cord blood of atopic mothers. ${ }^{10,11}$ On the contrary, Rindsjö et al..$^{12}$ reported that Treg cells in cord blood were not affected by the allergic status of the mother.

AR, an allergic inflammatory disorder of the upper respiratory tract, is influenced by heredity and environment, and epigenetics is hypothesized to mediate the relationship between them. ${ }^{13,14}$ Epigenetic modifications could alter the phenotype without modifying the genetic sequence. In addition, these epigenetic modifications can be transmitted from mother to offspring, suggesting epigenetics as a possible mechanism for the dramatic incidence changes of allergic diseases in recent decades. ${ }^{15}$ Epigenetic modifications contain histone modification,

Correspondence to: Yu Xu, MD, Department of Otolaryngology-Head and Neck Surgery, Renmin Hospital of Wuhan University, 238 Jiefang Rd, Wuhan 430060, China.

Tel: +86-02788041911; Fax: +86-02788042292; E-mail: xuy@whu.edu.cn Received: June 23, 2016; Revised: August 26, 2016; Accepted: September 29, 2016

- Lu Tan and Jing Ou contributed equally to this work.

- There are no financial or other issues that might lead to conflict of interest. 
noncoding RNAs, chromatin remodeling, and DNA methylation. DNA methylation is one of the most common epigenetic modifications in eukaryotic cells and its functions in allergic diseases have been enthusiastically debated in recent years. ${ }^{16,17}$ Forkhead box p3 (Foxp3) is the specific transcription factor of $\mathrm{CD} 4{ }^{+} \mathrm{CD} 25^{+}$Treg cells and is a critical regulator of their development and function. ${ }^{18,19}$ Down-regulated Foxp3 induces defectiveness of Treg cells function which may play an important role in onset of AR. In a research recruited 256 children with AR and/or asthma, Treg cells dysfunction and hypermethylation at CpG islands of Foxp3 promoter were detected. ${ }^{20}$ As a speculation, Foxp3 DNA methylation influencing Treg cells may be the pivotal point involved in the pathogenesis of AR.

In our prior research, ${ }^{21}$ we had constructed a stable AR mouse model stimulated with natural allergen-Dermatophagoides pteronyssinus (Der p) 1. This protocol was more similar to the natural process of sensitization compared with which stimulated with unnatural allergen-ovalbumin (OVA). Another crucial reason we chose Der p1 as the stimulus was that home dust mites were the major source of allergen and more than $50 \%$ of allergic diseases are attributed to them, ${ }^{22}$ especially in Southern China region. ${ }^{23-26}$ In this research, Der p1, as an environmental stimulus, was given to female mice before and during pregnancy to construct Der p 1-stimulated AR mice model.

In short, we hypothesized that not only Th1/Th2 balance but also Tregs had altered in AR mother and their offspring. Recent findings in epigenetics led us to speculate Foxp3 DNA methylation as a possible mechanism responsible for the association between the two generations.

\section{MATERIALS AND METHODS}

\section{Animals}

Female and male BALB/c mice (6-8 weeks old) were bought from Animal Experiment Center of Wuhan University. All animals were kept in a specific pathogen-free biohazard containment facility in Animal Experiment Center of Wuhan Universi- ty. All experimental procedures of this animal research were approved by the Institutional Animal Care and Use Committee of Wuhan University (No. SCXK-2008-0004).

\section{Experimental protocol}

Female mice were randomly divided into saline-stimulated female mice (Normal mother) group or Der $\mathrm{p}$ 1-stimulated female mice (AR mother) group, offspring of them were named as normal offspring group and AR offspring group, separately. After fed adaptively for 3 days, AR mother group were sensitized by initial intraperitoneal (i.p.) injections of $400 \mu \mathrm{L}$ phosphate-buffered saline (PBS) containing $1 \mu \mathrm{g}$ Der p1 (Indoor Biotechnologies, Charlottesville, VA, USA) and aluminum hydroxide ( $4 \mathrm{mg}$ ) on day 1 and day 7 . After the last maternal sensitization, the female mice were placed in cages to mate with normal male mice according to the female and male ratio $2: 1$ on day 8 . From day 21 to day 28, the female mice were intranasal challenged with $20 \mu \mathrm{L}$ PBS containing Der p 1 ( $2 \mu \mathrm{g})$ continuously. The normal mother group was sensitized and challenged with normal saline in the same way. The offspring of AR mother group (AR offspring) and normal mother group (normal offspring) were not stimulated with Der $\mathrm{p} 1$, and were humanely killed for analysis 3 days after birth (Fig. 1).

\section{Evaluation of symptoms of mother groups}

After the last challenge by Der $p$ 1, the frequencies of scratching nose and sneezing of maternal mice were counted within 30 minutes to evaluate the symptoms of AR in a quantitative way. Each mouse was observed for 10 minutes to record its symptom.

\section{Histopathologic analysis of nasal mucosae}

After mice were killed, nasal mucosae were excised. These tissues were immobilized in $10 \%$ neutral-buffered formalin and embedded in paraffin. The paraffin-embedded tissues were sectioned coronally by continuous microtoming at a thickness of $4 \mu \mathrm{m}$. Histologic changes of nasal mucosae in mice of all

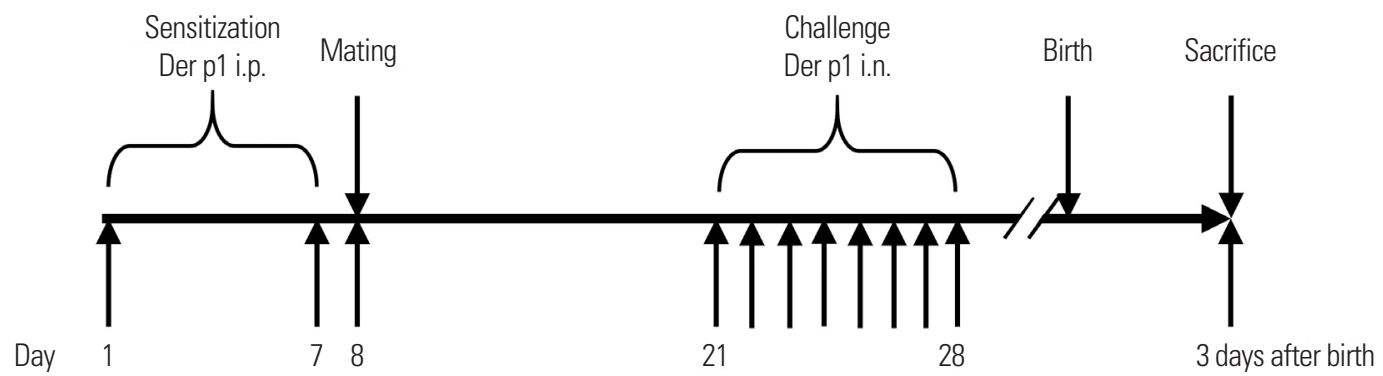

Fig. 1. Experimental Protocol. After fed adaptively for 3 days, maternal mice were sensitized by initial intraperitoneal (i.p.) injections of $400 \mu \mathrm{L}$ phosphate-buffered saline (PBS) containing 1 ug Der p1 (Indoor Biotechnologies, Charlottesville, Virginia) and aluminum hydroxide (4 mg) on day 1 and day 7 . After the last maternal sensitization, the female mice were placed in cages to mate with normal male mice according to the female and male ratio $2: 1$ on day 8 . From day 21 to day 28 , the female mice were intranasal challenged with $20 \mu \mathrm{L}$ PBS containing Der $p 1(2 \mu \mathrm{g})$ continuously. The normal mother group was sensitized and challenged with normal saline in the same way. The offspring were not stimulated with Der $p 1$, and were humanely killed for analysis 3 days after birth. 
groups were evaluated through hematoxylin-eosin (HE) staining for eosinophils and periodic acid-schiff stain (PAS) for goblet cells.

\section{Measurement of cytokines in sera of mother and spleen homogenates of offspring}

Bloods of mother groups were collected from mice canthus and centrifuged for 20 minutes at 2,000 $\times$ rpm to isolate the sera. The spleens of offspring were ground into homogenates and centrifuged for 20 minutes at $2,000 \times$ rpm to get the supernatant. The levels of interleukin (IL)-4, interferon (IFN)- $\gamma$, IL10 , transforming growth factor (TGF)- $\beta$, IL-17 in the sera and spleen homogenates were measured by enzyme-linked immunosorbent assay (ELISA) based on the manufacturer's instructions (Biofavor, Wuhan, China).

\section{Flow cytometry analysis of $\mathrm{CD} 4^{+} \mathrm{CD} 25^{+} \mathrm{FOXP3} 3^{+}$Treg cells}

Single-cell suspensions of lymphocytes were extracted from fresh spleens tissue using Mouse Spleen Lymphocyte Separation Medium Kit (TBD Science, Tianjin, China). Single-cell suspensions of lymphocytes were stained for Treg cells using Mouse Regulatory T Cell Staining Kit (eBioscience, San Diego, CA, USA) with anti-CD4-FITC, anti-CD25-APC, and antiFOXP3-PE according to the manufacturer's instructions. Flow cytometry was performed and analyzed on BD FACSCalibur flow cytometer (BD Biosciences, San Jose, CA, USA).

\section{Quantitative reverse transcriptase polymerase chain reaction (qRT-PCR) analysis of Foxp3 mRNA}

Based on mRNA sequences of the Foxp3 in GenBank, the primers for these genes were designed with Primer Express 5.0 software (Applied Biosystems, Inc., Foster City, CA, USA). These primers were synthesized by Sangon Biotech, Inc. (Shanghai, China). The up-stream primer for Foxp3 was 5'-GAAACAGCACATTCCCAGAGTTC-3' and its down-stream primer was 5'-ATGGCCCAGCGGATGAG-3'. Gapdh was used as the internal control. The up-stream primer for Gapdh was 5'-AAGGCTGGGGCTCATTTG-3' and the down-stream primer was $5^{\prime}$-AGGGGCCATCCACAGTCTTT-3'

Total RNA was extracted from spleens using the Total RNA Isolation Kit (Invitrogen, Carlsbad, CA, USA). The cDNA was synthesized using the First Strand cDNA Synthesis Kit (Tiangen, Beijing, China) according to the manufacturer's instructions. For polymerase chain reaction (PCR) reaction, $2.5 \mu \mathrm{L}$ of reverse transcribed cDNA template was used as template. The quantitative real-time reverse transcription polymerase chain reaction (qRT-PCR) was performed using RT-PCR Kit (Takara, Dalian, China). The PCR conditions were set as follows: incubation at $95^{\circ} \mathrm{C}$ for 10 minutes, followed by 40 cycles of $95^{\circ} \mathrm{C}$ for 15 seconds, $60^{\circ} \mathrm{C}$ for 60 seconds with a final extension step at $60^{\circ} \mathrm{C}$ for 5 minutes. Data were analyzed using the $2^{-\Delta \Delta \mathrm{CT}}$ method as previously described.$^{27}$ Fluorescent quantitative PCR machine,
PCR machine and high throughput DNA Synthesizer were purchased from Applied Biosystems, Inc. (Norwalk, CT, USA).

\section{DNA methylation level of Foxp3}

Genomic DNA was extracted from spleen tissue and treated by bisulfite conversion. Bisulfite modified DNA was subjected to PCR under conditions set as follows: incubation at $98^{\circ} \mathrm{C}$ for 4 minutes, followed by 40 cycles of $94^{\circ} \mathrm{C}$ for 45 seconds, $66^{\circ} \mathrm{C}$ for 45 seconds, $72^{\circ} \mathrm{C}$ for 60 seconds with a final extension step at $72^{\circ} \mathrm{C}$ for 8 minutes. The up-stream primer for Foxp 3 was 5'-TTTTAGATGATTTGTAAAGGGTAAAG-3' and its downstream primer was 5'-ATCAACCTAACTTATAAAAAACTACCAC-3'. DNA isolation, bisulfite conversion of genomic DNA and Foxp3 DNA methylation analysis for $6 \mathrm{CpG}$ islands in the Foxp3 promoter region were performed by Sangon Biotech, Inc. (Shanghai, China).

\section{Statistical analysis}

Data were presented as mean \pm standard error of mean. Data analysis was performed using SPSS statistical software, version 22.0 (IBM, Chicago, IL, USA), and GraphPad Prism software, version 5.0 (GraphPad Software, San Diego, CA, USA). Unpaired Student's $t$ test was used to determine differences between two groups. $P<0.05$ was considered statistically significant. $P<0.01$ was considered obvious statistical significant.

\section{RESULTS}

\section{Allergic symptoms of maternal mice}

The frequencies of nose scratching were $9.80 \pm 1.74$ in $10 \mathrm{~min}$ utes in the AR mother group and $2.20 \pm 0.13$ in the normal mother group. The frequencies of sneezing were $3.10 \pm 0.22$ in 10 minutes in the AR mother group and $0.80 \pm 0.04$ in the normal mother group. The frequencies of both symptoms were higher in the AR mother group than the normal control group $(P<0.05)$.

\section{HE and PAS staining of nasal mucosae}

In normal mother group, there were little eosinophils in the nasal lamina propria. Hyperplasia of gland cells and infiltration of other inflammatory cells were not discovered in this group. The structure of pseudostratified ciliated columnar epithelium was intact and the cilia were continuous without impairment or exfoliation. A few tall and thin Goblet cells were noticed in pseudostratified ciliated columnar epithelium. Similar histopathologic conditions were found in normal offspring group. In AR mother and AR offspring group, infiltration of eosinophils and lymphocytes, tissue edema, hemangiectasis, and hyperplasia of gland cells could be discovered in lamina propria. In addition, reduction, exfoliation, and discontinuity of cilia as well as hyperplasia and hypertrophy of goblet cells could be discovered in pseudostratified ciliated columnar epithelium (Fig. 2). 


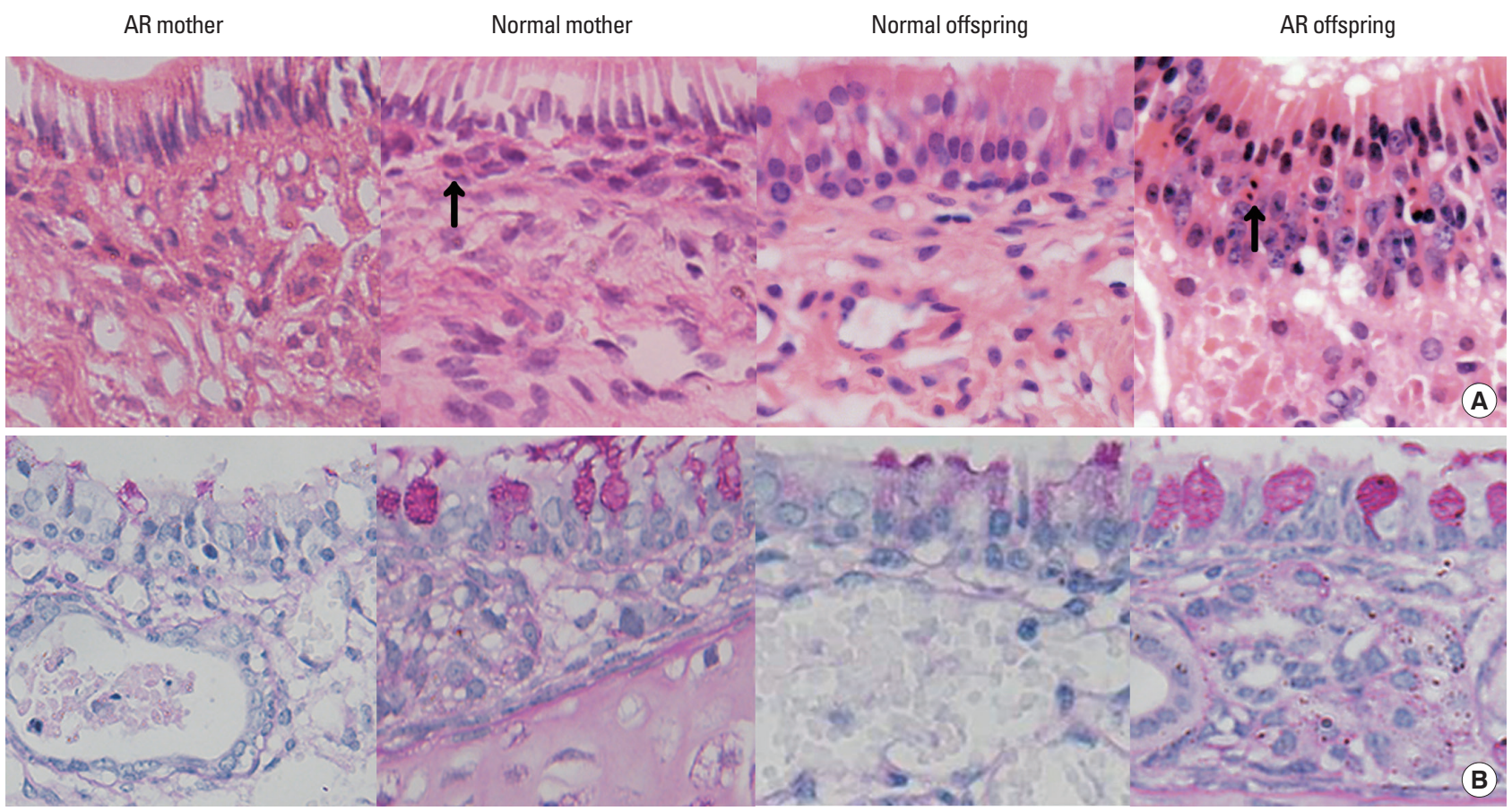

Fig. 2. HE and PAS staining of nasal mucosae (original magnification $\times 400)$. (A) The cytoplasm of eosinophils (black arrows) in the nasal lamina propria (LP) stains red by HE. (B) The cytoplasm of goblet cell in the nasal epithelial layer stains aubergine by PAS. Histopathology showed eosinophils accumulation and goblet cells hyperplasia in the nasal lamina propria in AR mother group and AR offspring group. $\mathrm{HE}$, hematoxylin-eosin; PAS, periodic acid-schiff stain; AR, allergic rhinitis.
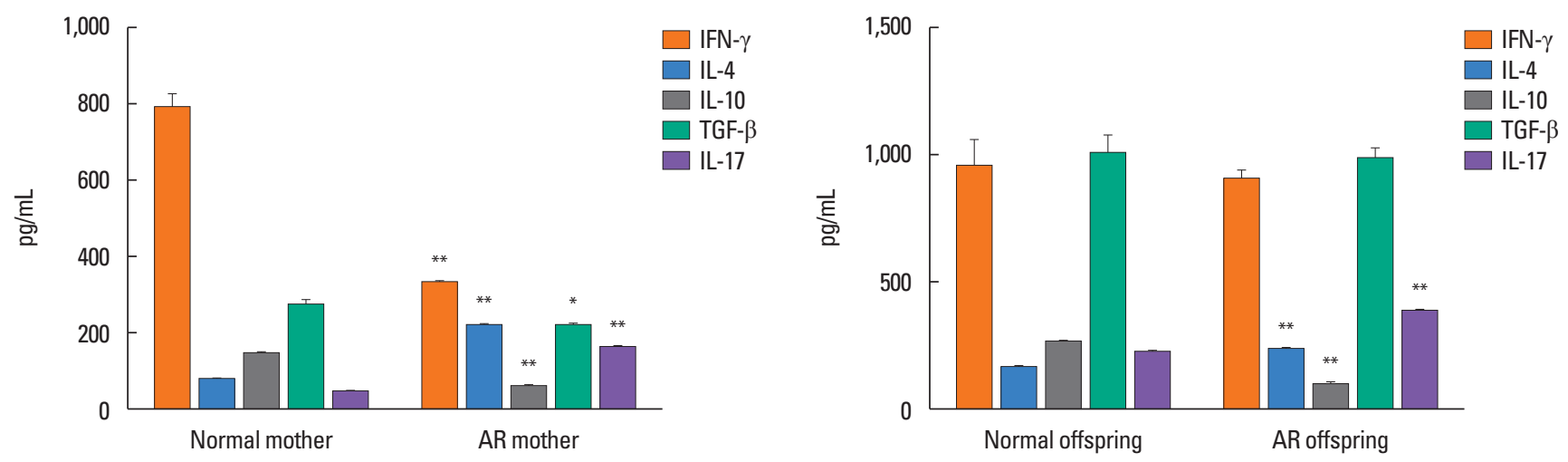

Fig. 3. Cytokines sections in sera of mother and spleen homogenates of offspring. The concentrations of IFN- $\gamma$, TGF- $\beta$, IL-10, IL-17, and IL-4 in sera of mother and spleen homogenates of offspring were measured by ELISA. ( $\mathrm{n}=5$ for each group; ${ }^{*} P<0.05,{ }^{* *} P<0.01$ ). IFN, Interferon; TGF, transforming growth factor; IL, interleukin; ELISA, enzyme-linked immunosorbent assay.

\section{Concentrations of cytokines in sera of mother and spleen homogenates of offspring}

Compared with the normal mother group, the levels of IFN- $\gamma$, IL-10, and TGF- $\beta$ declined in the AR mother group, while the levels of IL-17 and IL- 4 were on the rise. Similar tendency was presented in the offspring groups. That is, AR offspring had lower secretion of IL-10 and higher secretion of IL-17 and IL-4 than normal offspring (Fig. 3).

\section{$\mathrm{CD}^{+} \mathrm{CD}^{2} 5^{+} \mathrm{FOXP3}^{+}$Treg cells of total lymphocytes in spleens}

$\mathrm{CD}^{+} \mathrm{CD} 25^{+} \mathrm{FOXP}^{+}$Tregs count was detected by flow cytome- try and transform to the percentage of total lymphocytes. Treg cell rate in the AR mother group $(0.58 \% \pm 0.01 \%)$ was significantly lower than that of the normal mother group $(3.05 \% \pm$ $0.26 \%)(P<0.01)$. Similarly, $\mathrm{CD} 4^{+} \mathrm{CD} 25^{+} \mathrm{FOXP}^{+}$Treg cells rate in the AR offspring group $(1.18 \% \pm 0.17 \%)$ decreased remarkably compared with the normal offspring group $(2.86 \% \pm$ $0.31 \%)(P<0.01)$ (Fig. 4).

\section{Foxp3 mRNA expressions}

Compared with normal controls, Foxp 3 mRNA in the AR mother group were significantly down-regulated $(1.026 \pm 0.060$ 


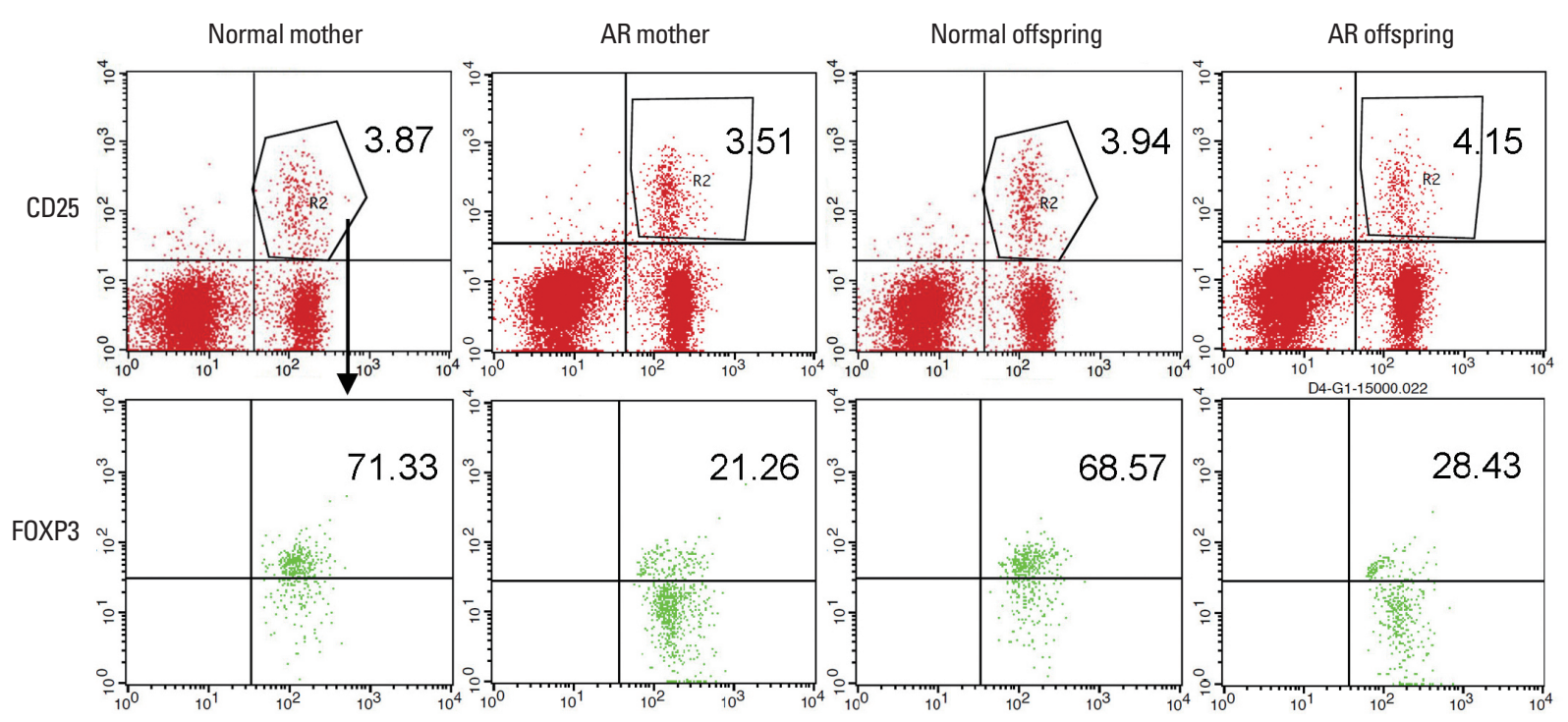

CD4
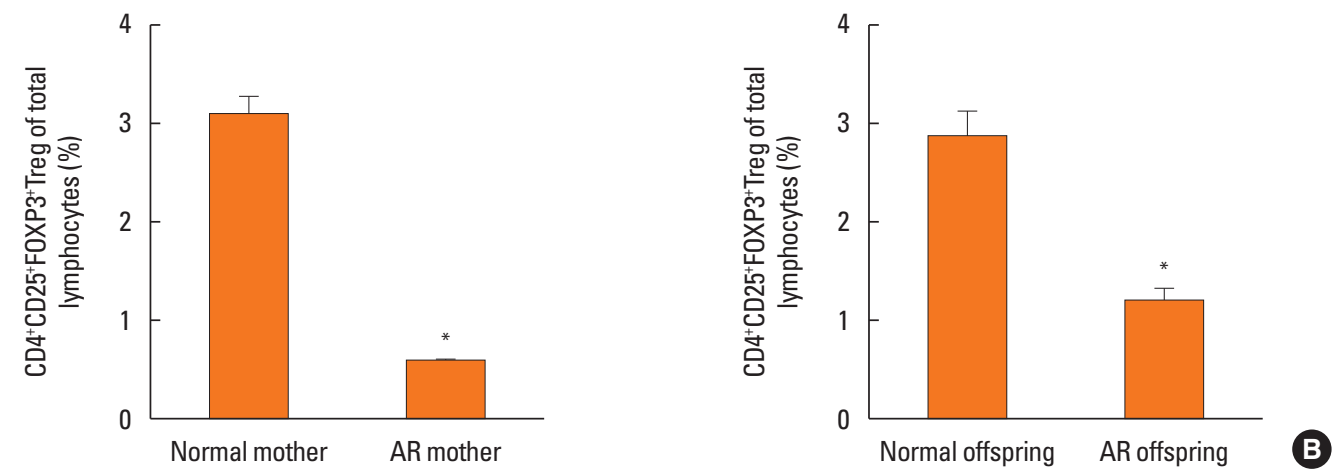

Fig. 4. CD4+CD25+FOXP3 ${ }^{+}$Tregs of total lymphocytes in spleens. Treg cells count in the spleen was measured by flow cytometry. (A) The analysis of CD4 vs FOXP3 expression was gated in $\mathrm{CD} 4^{+} \mathrm{CD} 25^{+}$cells. (B) $\mathrm{CD} 4^{+} \mathrm{CD} 25^{+} \mathrm{FOXP3} 3^{+}$Tregs were calculated in each group ( $\mathrm{n}=5$ for each group; ${ }^{*} P<0.01$ ).
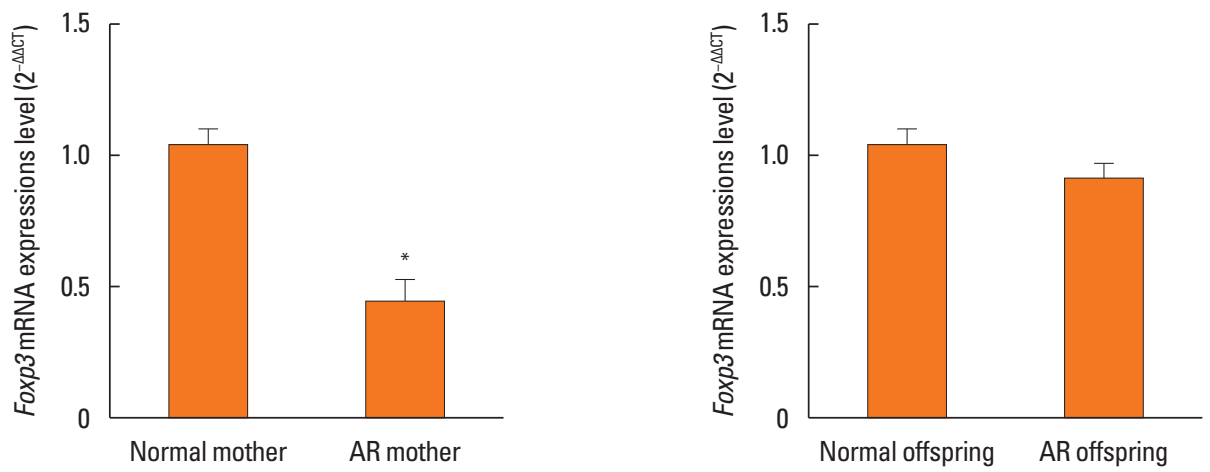

Fig. 5. Foxp3 mRNA Expressions. Foxp3 mRNA expression level in the spleen mononuclear cells was measured by RT-PCT. Relative Foxp3 mRNA levels were analyzed using the $2^{-\triangle \Delta C T}$ method $\left(n=4-5\right.$ for each group; $\left.{ }^{*} P<0.01\right)$.

vs $0.433 \pm 0.084, P<0.01)$. For the offspring, Foxp 3 mRNA expression in the AR offspring group have a tendency of decrease compared with the normal offspring group, but the difference was not obvious ( $1.035 \pm 0.058$ vs $0.898 \pm 0.059, P>0.05$ ) (Fig. 5).

\section{Foxp3 DNA methylation level}

We used bisulfite-assisted genomic sequencing method (BSP) to study six $\mathrm{CpG}$ islands in the Foxp3 promoter region. We set the transcription start as the $+1 \mathrm{bp}$. These $\mathrm{CpG}$ islands located $-200,-70,-61,-52,-49$, and -34 in the sequence and were la- 

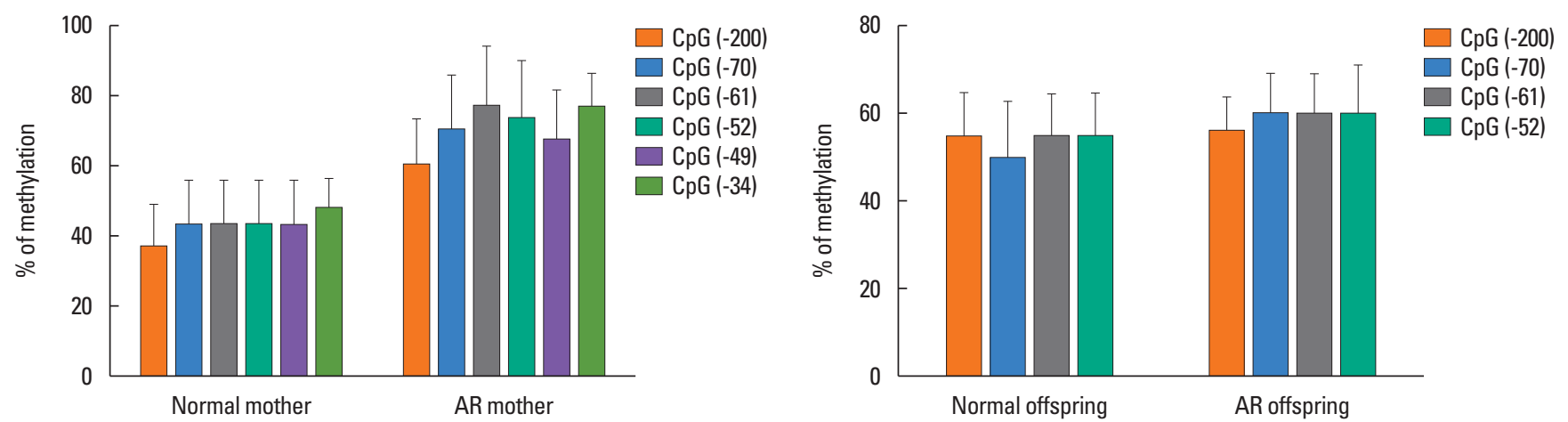

Fig. 6. Foxp3 DNA methylation level. Six CpG islands methylation level in Foxp3 promoter region measured by Bisulfite sequencing PCR. CpG islands methylation levels in the AR mother group had a tendency of elevation compared to normal controls. While CpG (-200), CpG (-70), CpG (-61), and CpG (-52) methylation levels in the AR offspring group were slightly increased than which in normal controls. But all the differences of $\mathrm{CpG}$ islands methylation levels were not distinguishable by statistical analysis ( $n=4-5$ for each group; $P>0.05)$.

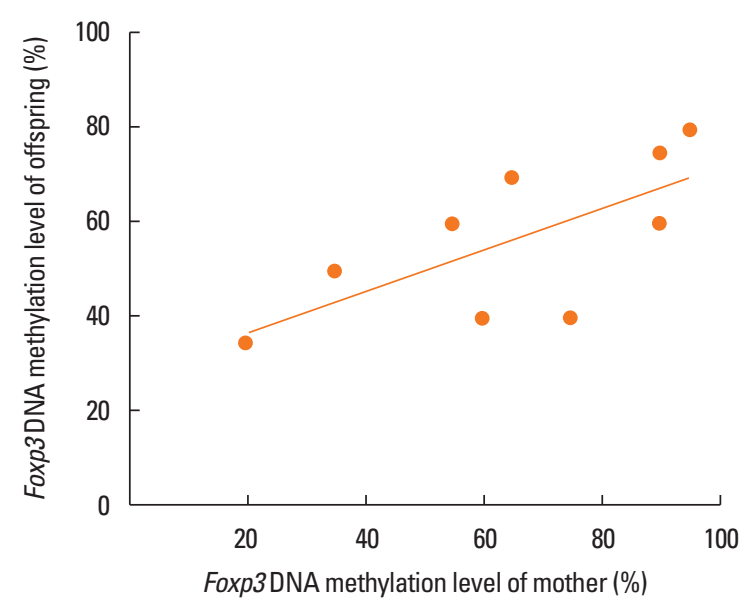

Fig. 7. Correlation analysis between Foxp3 DNA methylation level of mother and that of offspring. Average DNA methylation level of CpG (-200), CpG (-70), $\mathrm{CpG}(-61)$ and $\mathrm{CpG}(-52)$ in all offspring was paired with that in their respective mothers. Based on linear regression model, correlation analysis demonstrated that there was significant positive correlation between Foxp3DNA methylation level of mother and that of offspring $(r=0.681, P<0.05)$

beled as CpG (-200), CpG (-70), CpG (-61), CpG (-52), CpG (-49), and CpG (-34). Our data suggested that all the six CpG islands methylation percentages in the AR mother group had a tendency of elevation compared to normal controls. While CpG (-200), CpG (-70), CpG (-61), and CpG (-52) methylation percentages in the AR offspring group were slightly increased than which in normal controls. But all the differences of $\mathrm{CpG}$ islands methylation percentages were not distinguishable by statistical analysis $(P>0.05)$ (Fig. 6).

Furthermore, correlation analysis was performed based on linear regression model. We paired the average DNA methylation level of CpG (-200), CpG (-70), CpG (-61), and CpG (-52) in all offspring with that in their respective mothers. Result demonstrated that there was significant positive correlation between Foxp3 DNA methylation level in mother and that in off- spring $(\mathrm{r}=0.681, P<0.05)$ (Fig. 7$)$.

\section{Correlation analysis between Foxp3 DNA methylation and mRNA expression}

To verify the effect of Foxp3 DNA methylation on Treg cells, we paired the average DNA methylation level of CpG (-200), CpG (-70), CpG (-61), and CpG (-52) with Foxp3 mRNA expression in each individual mouse. Based on linear regression model, results demonstrated that there was significant negative correlation between average Foxp3 DNA methylation level and mRNA expression level in the mother groups $(\mathrm{r}=0.924, P<0.01)$ and the offspring groups $(\mathrm{r}=0.749, P<0.05)$ (Fig. 8).

\section{DISCUSSION}

Most current studies share the view that AR, characterized by allergic inflammatory response, is the result of Th2 polarization in the $\mathrm{CD} 4^{+} \mathrm{Th}$ cell differentiation pathway. In our study, without any allergenic stimulation, AR offspring had more inflammatory cells, such as eosinophils, infiltrating into the nasal mucosa than normal offspring. ELISA analysis revealed the domination of IL- 4 and IL-17 in both AR mother and their offspring. This indicated the Th2-skewed immune state in young offspring mice of AR mother. Clinical researches had similar results, Fu et al. ${ }^{11}$ observed significantly increased Th2 cells in cord blood of newborns of allergic mother. In addition, reduced Th1/Th2 ratio in cord blood caused a higher risk to develop atopic dermatitis $(\mathrm{AD})$ for these children.

In addition to Th1/Th2 imbalance theory, the discovery of Treg cells made a key supplement for AR mechanisms. Treg cells have vital functions in immune regulation and immune suppression. Studies manifested that Treg cells counts and functions could be influenced by maternal farm exposure, ${ }^{27,28}$ combustion generated particulate matter exposure ${ }^{29}$ and fiber diet, ${ }^{30}$ then subsequently influence the allergic diseases (asthma, food allergy, and atopic dermatitis) of offspring. However, 

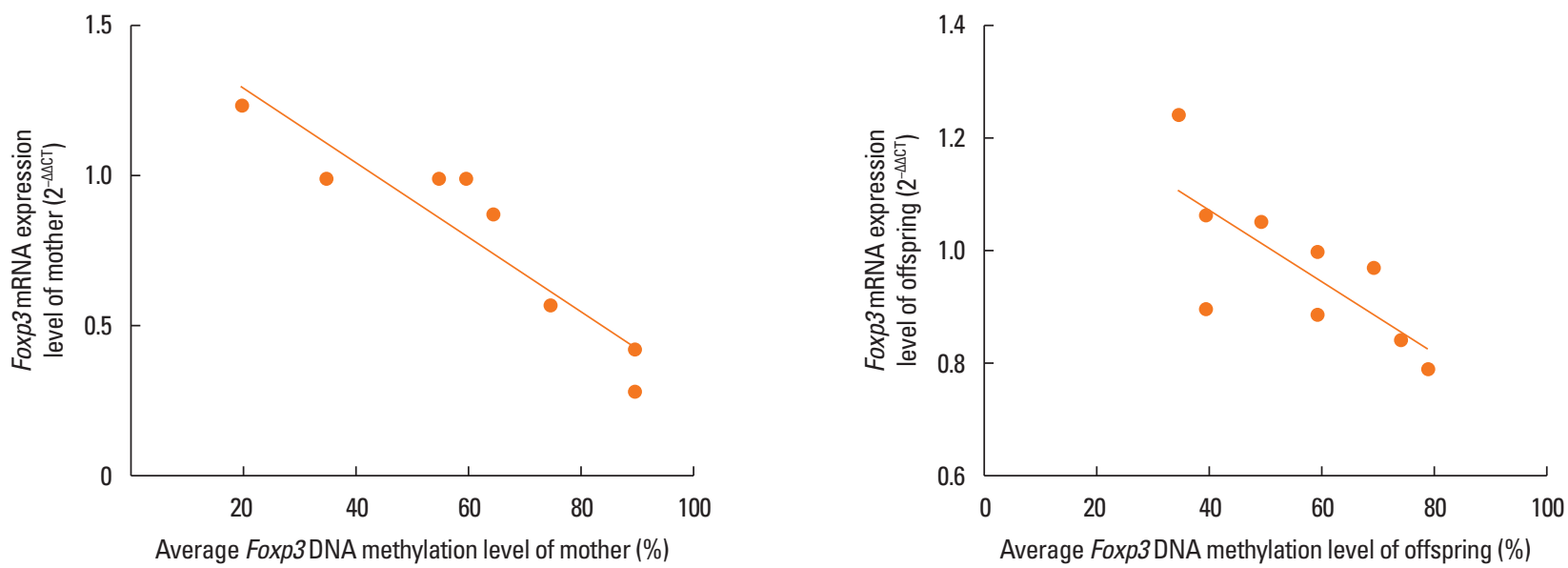

Fig. 8. Correlation analysis between Foxp3 DNA methylation and mRNA expression. Average DNA methylation level of CpG (-200), CpG (-70), CpG (-61), and CpG (-52) was paired with Foxp3 mRNA expression in each individual mouse. Based on linear regression model, result demonstrated that there was significant negative correlation between average Foxp3 DNA methylation level and mRNA expression level in mother groups $(r=0.924, P<0.01)$ and offspring groups $(r=0.749, P<0.05)$.

evidence verifying the roles of Treg cells in the maternal transmission of AR susceptibility is insufficient. Our data showed that, by Derp 1-stimulated AR mice model, the Treg cells counts decreased in both AR mother group and AR offspring group. In addition, Foxp3 mRNA expressions were inhibited in the AR mother group. IL-10, an immunosuppressive cytokine party secreted by Treg cells, was significantly inhibited in AR mother and their offspring. This finding implicated the suppression of Treg cells in both cell count and function, and that was closely associated with the inborn aberrant immune state in AR offspring.

DNA methylation and other epigenetic modifications may play important roles in the process of maternal transmission of AR risk and Treg cells function regulation. DNA methylation typically occurs at cytosines within $\mathrm{CpG}$ islands. Methylation of these $\mathrm{CpG}$ islands results in the condensation of chromatin and decreased accessibility of target sequences, down-regulates the transcription and expression of gene subsequently. ${ }^{31}$ Differential DNA methylation at specific regions have been identified to be associated with allergic diseases, including loci of IFNG, ${ }^{32}$ $I L 4,{ }^{33} I L 13,{ }^{33,34}$ and thymic stromal lymphopoietin (TSLP) ${ }^{35}$ CpG methylation of $S T A T 4^{36}$ and $T-b e t^{37}$ loci may lead silencing of corresponding genes during Th2 differentiation. DNA methylation of GATA3, Th2 key transcription factor, is modified by oral contraceptives ${ }^{38}$ or early epicutaneous immunotherapy. ${ }^{39}$ Whereafter it affects the risk of asthma or further sensitization.

We focus our attention on Treg cells and Foxp3. In previous research we found the CpG islands hypermethylation at FOXP3 promoter in peripheral blood mononuclear cells of AR patients (unpublished data). Similarly, very recent works had also demonstrated the close relationship between FOXP3 DNA methylation and Th2-mediated allergic inflammation. Hinz et al $.^{40} \mathrm{de}-$ tected Treg cell numbers via DNA demethylation in the FOXP3 Treg-cell-specific demethylated region (TSDR) and found that offspring of allergic parents had lower Treg cell numbers in cord blood and higher risk to develop atopic dermatitis. In a general population-derived birth cohort,infants who developed food allergy had a decreased proportion of Treg cells and lower demethylation FOXP3 in $\mathrm{CD} 4{ }^{+} \mathrm{T}$ cells. ${ }^{41}$ It is conceivable that the same changes might happen in Treg cells of these two generations. So this time we detected the methylation of Foxp3 promoter in AR mice mother and their offspring. No significant difference in methylation level of Foxp 3 was observed between AR mice and normal controls in the mother groups nor in the offspring groups. Possible reasons for the negative result in this study are as follows: Foxp3 gene has several conserved CpGrich regions which located in the upstream enhancer (far upstream of the transcriptional start site), promoter (immediately upstream to the Foxp3 transcriptional start site), and intronic enhancer region, namely TSDR (present between noncoding exons-2b and-1). ${ }^{31,42}$ We only analyzed a segment in Foxp 3 promoter and found the tendency of Foxp 3 promoter hypermethylation in AR mice mother and their offspring. Detecting more mice samples and more $\mathrm{CpG}$-rich regions may distinguish the difference. Other epigenetic modifications, such as histone modification, noncoding RNAs, chromatin remodeling, may be responsible for the changes of Treg cells too. Previous researches indicated that classic genetic inheritance ${ }^{43,44}$ and perinatal transfer of maternal mediators (such as allergens, antibodies or cytokines) via placenta or breast milk ${ }^{45-47}$ might also be responsible for maternal effect.

Further correlation analysis demonstrated that there was significantly positive correlation between Foxp3 DNA methylation level of mother and that of offspring. Negative correlation between average Foxp3 DNA methylation level and mRNA expression level was also found in both mother groups and offspring groups. These results partly verified our hypothesis that maternal Foxp3 DNA hypermethylation can be transmitted to 
offspring and this is associated with the recession of Treg cells in offspring.

In conclusion, this study highlights the important roles of Treg cells in AR mechanisms and the process of maternal transmission of AR susceptibility. Neonatal offspring of AR mother are born with abnormal immune state and this is closely associated with the recession of Treg cells. Thus, these offspring become more vulnerable to AR. Although AR offspring show the potential susceptibility to AR, whether or not they would develop AR is still associated with later allergens and other immune stimulation exposures. Epigenetic or other mechanisms concerning Treg cells still need more studies to uncover.

\section{ACKNOWLEDGMENTS}

This study was supported by grant from the National Natural Science Foundation of China (No. 81371070).

\section{REFERENCES}

1. Bousquet PJ, Leynaert B, Neukirch F, Sunyer J, Janson CM, Anto J, et al. Geographical distribution of atopic rhinitis in the European Community Respiratory Health Survey I. Allergy 2008;63:1301-9.

2. Bousquet J, Schünemann HJ, Samolinski B, Demoly P, Baena-Cagnani $\mathrm{CE}$, Bachert $\mathrm{C}$, et al. Allergic rhinitis and its impact on asthma (ARIA): achievements in 10 years and future needs. J Allergy Clin Immunol 2012;130:1049-62.

3. Zheng M, Wang X, Bo M, Wang K, Zhao Y, He F, et al. Prevalence of allergic rhinitis among adults in urban and rural areas of china: a population-based cross-sectional survey. Allergy Asthma Immunol Res 2015;7:148-57.

4. Litonjua AA, Carey VJ, Burge HA, Weiss ST, Gold DR. Parental history and the risk for childhood asthma. Does mother confer more risk than father? Am J Respir Crit Care Med 1998;158:176-81.

5. Wright AL, Holberg CJ, Taussig LM, Martinez FD. Factors influencing the relation of infant feeding to asthma and recurrent wheeze in childhood. Thorax 2001;56:192-7.

6. Lim RH, Kobzik L, Dahl M. Risk for asthma in offspring of asthmatic mothers versus fathers: a meta-analysis. PLoS One 2010;5:e10134.

7. Fang SP, Tanaka T, Tago F, Okamoto T, Kojima S. Immunomodulatory effects of gyokuheifusan on INF-gamma/IL-4 (Th1/Th2) balance in ovalbumin (OVA)-induced asthma model mice. Biol Pharm Bull 2005;28:829-33.

8. Palomares O, Yaman G, Azkur AK, Akkoc T, Akdis M, Akdis CA. Role of Treg in immune regulation of allergic diseases. Eur J Immunol 2010;40:1232-40.

9. Torgerson TR, Linane A, Moes N, Anover S, Mateo V, Rieux-Laucat F, et al. Severe food allergy as a variant of IPEX syndrome caused by a deletion in a noncoding region of the FOXP3 gene. Gastroenterology 2007;132:1705-17.

10. Schaub B, Liu J, Höppler S, Haug S, Sattler C, Lluis A, et al. Impairment of T-regulatory cells in cord blood of atopic mothers. J Allergy Clin Immunol 2008;121:1491-9, 1499.e1-13.

11. Fu Y, Lou H, Wang C, Lou W, Wang Y, Zheng T, et al. T cell subsets in cord blood are influenced by maternal allergy and associated with atopic dermatitis. Pediatr Allergy Immunol 2013;24:178-86.
12. Rindsjö E, Joerink M, Johansson C, Bremme K, Malmström V, Scheynius A. Maternal allergic disease does not affect the phenotype of $\mathrm{T}$ and $\mathrm{B}$ cells or the immune response to allergens in neonates. Allergy 2010;65:822-30.

13. Martino D, Kesper DA, Amarasekera M, Harb H, Renz H, Prescott S. Epigenetics in immune development and in allergic and autoimmune diseases. J Reprod Immunol 2014;104-105:43-8.

14. DeVries A, Vercelli D. Epigenetics in allergic diseases. Curr Opin Pediatr 2015;27:719-23.

15. Pfefferle PI, Pinkenburg O, Renz H. Fetal epigenetic mechanisms and innate immunity in asthma. Curr Allergy Asthma Rep 2010;10: 434-43.

16. Yang IV, Schwartz DA. Epigenetic mechanisms and the development of asthma. J Allergy Clin Immunol 2012;130:1243-55.

17. Lockett GA, Patil VK, Soto-Ramírez N, Ziyab AH, Holloway JW, Karmaus W. Epigenomics and allergic disease. Epigenomics 2013; 5: 685-99.

18. Fontenot JD, Gavin MA, Rudensky AY. Foxp3 programs the development and function of CD4+CD25+ regulatory T cells. Nat Immunol 2003;4:330-6.

19. O'Garra A, Vieira P. Twenty-first century Foxp3. Nat Immunol 2003; 4:304-6.

20. Hew KM, Walker AI, Kohli A, Garcia M, Syed A, McDonald-Hyman C, et al. Childhood exposure to ambient polycyclic aromatic hydrocarbons is linked to epigenetic modifications and impaired systemic immunity in T cells. Clin Exp Allergy 2015;45:238-48.

21. Ou J, Shi W, Xu Y, Tao Z. Intranasal immunization with DNA vaccine coexpressing Der $\mathrm{p} 1$ and ubiquitin in an allergic rhinitis mouse model. Ann Allergy Asthma Immunol 2014;113:658-665.e1.

22. Platts-Mills TA, Chapman MD. Dust mites: immunology, allergic disease, and environmental control. J Allergy Clin Immunol 1987; 80:755-75.

23. Feng $M$, Sun $W$, Cheng X. Seasonal dynamics and distribution of house dust mites in China. Biosci Trends 2009;3:210-5.

24. Feng M, Yang B, Zhuang YJ, Yanagi U, Cheng XJ. A study on indoor environment contaminants related to dust mite in dwellings of allergic asthma patients and of healthy subjects. Biosci Trends 2012; 6:7-9.

25. Wang Y, Xiong L, Yin X, Wang J, Zhang Q, Yu Z, et al. House dust mite allergen levels in households and correlation with allergic rhinitis symptoms. Am J Rhinol Allergy 2014;28:193-6.

26. Yu JM, Luo QH, Sun JL, Shi CL, Yin J, Zhou YL, et al. Diversity of House dust mite species in Xishuangbanna Dai, a tropical rainforest region in southwest China. Biomed Res Int 2015;2015:421716.

27. Schaub B, Liu J, Höppler S, Schleich I, Huehn J, Olek S, et al. Maternal farm exposure modulates neonatal immune mechanisms through regulatory T cells. J Allergy Clin Immunol 2009;123:774782.e5.

28. Lewis MC, Inman CF, Patel D, Schmidt B, Mulder I, Miller B, et al. Direct experimental evidence that early-life farm environment influences regulation of immune responses. Pediatr Allergy Immunol 2012;23:265-9.

29. Wang P, You D, Saravia J, Shen H, Cormier SA. Maternal exposure to combustion generated PM inhibits pulmonary Thl maturation and concomitantly enhances postnatal asthma development in offspring. Part Fibre Toxicol 2013;10:29.

30. Thorburn AN, McKenzie CI, Shen S, Stanley D, Macia L, Mason LJ, et al. Evidence that asthma is a developmental origin disease influenced by maternal diet and bacterial metabolites. Nat Commun 
2015;6:7320.

31. Huehn J, Polansky JK, Hamann A. Epigenetic control of FOXP3 expression: the key to a stable regulatory T-cell lineage? Nat Rev Immunol 2009;9:83-9.

32. Brand S, Kesper DA, Teich R, Kilic-Niebergall E, Pinkenburg O, Bothur E, et al. DNA methylation of TH1/TH2 cytokine genes affects sensitization and progress of experimental asthma. J Allergy Clin Immunol 2012;129:1602-1610.e6.

33. Yang IV, Pedersen BS, Liu A, O'Connor GT, Teach SJ, Kattan M, et al. DNA methylation and childhood asthma in the inner city. J Allergy Clin Immunol 2015;136:69-80.

34. Li JY, Zhang Y, Lin XP, Ruan Y, Wang Y, Wang CS, et al. Association between DNA hypomethylation at IL13 gene and allergic rhinitis in house dust mite-sensitized subjects. Clin Exp Allergy 2016;46: 298-307.

35. Wang IJ, Chen SL, Lu TP, Chuang EY, Chen PC. Prenatal smoke exposure, DNA methylation, and childhood atopic dermatitis. Clin Exp Allergy 2013;43:535-43.

36. Shin HJ, Park HY, Jeong SJ, Park HW, Kim YK, Cho SH, et al. STAT4 expression in human T cells is regulated by DNA methylation but not by promoter polymorphism. J Immunol 2005;175:7143-50.

37. Hewitt SL, High FA, Reiner SL, Fisher AG, Merkenschlager M. Nuclear repositioning marks the selective exclusion of lineage-inappropriate transcription factor loci during $\mathrm{T}$ helper cell differentiation. Eur J Immunol 2004;34:3604-13.

38. Guthikonda K, Zhang H, Nolan VG, Soto-Ramírez N, Ziyab AH, Ewart S, et al. Oral contraceptives modify the effect of GATA3 polymorphisms on the risk of asthma at the age of 18 years via DNA methylation. Clin Epigenetics 2014;6:17.
39. Mondoulet L, Dioszeghy V, Puteaux E, Ligouis M, Dhelft V, Plaquet $\mathrm{C}$, et al. Specific epicutaneous immunotherapy prevents sensitization to new allergens in a murine model. J Allergy Clin Immunol 2015;135:1546-1557.e4.

40. Hinz D, Bauer M, Röder S, Olek S, Huehn J, Sack U, et al. Cord blood Tregs with stable FOXP3 expression are influenced by prenatal environment and associated with atopic dermatitis at the age of one year. Allergy 2012;67:380-9.

41. Zhang Y, Collier F, Naselli G, Saffery R, Tang ML, Allen KJ, et al. Cord blood monocyte-derived inflammatory cytokines suppress IL-2 and induce nonclassic "T(H)2-type" immunity associated with development of food allergy. Sci Transl Med 2016;8:321ra8.

42. Lal G, Bromberg JS. Epigenetic mechanisms of regulation of Foxp3 expression. Blood 2009;114:3727-35.

43. Zhang Y, Lin X, Desrosiers M, Zhang W, Meng N, Zhao L, et al. Association pattern of interleukin-1 receptor-associated kinase- 4 gene polymorphisms with allergic rhinitis in a Han Chinese population. PLoS One 2011;6:e21769.

44. Xu Y, Zhang JX. Interleukin-4 receptor alpha-chain polymorphisms and susceptibility to allergic rhinitis: a meta-analysis. Eur Arch Otorhinolaryngol 2014;271:2205-12.

45. Bønnelykke K, Pipper CB, Bisgaard H. Transfer of maternal IgE can be a common cause of increased IgE levels in cord blood. J Allergy Clin Immunol 2010;126:657-63.

46. Cook-Mills JM. Maternal influences over offspring allergic responses. Curr Allergy Asthma Rep 2015;15:501.

47. Lodge CJ, Dharmage SC. Breastfeeding and perinatal exposure, and the risk of asthma and allergies. Curr Opin Allergy Clin Immunol 2016;16:231-6. 